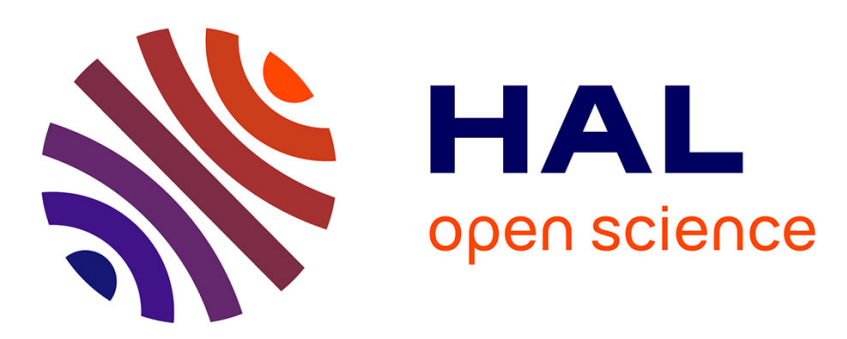

\title{
OPTICAL CHARACTERIZATION OF Nd3+ DOPED CaF2 LAYERS GROWN BY MOLECULAR BEAM EPITAXY
}

\author{
L. Bausa, R. Legros, A. Muñoz-Yagüe
}

\section{- To cite this version:}

L. Bausa, R. Legros, A. Muñoz-Yagüe. OPTICAL CHARACTERIZATION OF Nd3+ DOPED CaF2 LAYERS GROWN BY MOLECULAR BEAM EPITAXY. Journal de Physique IV Proceedings, 1991, 01 (C7), pp.C7-297-C7-301. 10.1051/jp4:1991780 . jpa-00251023

HAL Id: jpa-00251023

https://hal.science/jpa-00251023

Submitted on 1 Jan 1991

HAL is a multi-disciplinary open access archive for the deposit and dissemination of scientific research documents, whether they are published or not. The documents may come from teaching and research institutions in France or abroad, or from public or private research centers.
L'archive ouverte pluridisciplinaire HAL, est destinée au dépôt et à la diffusion de documents scientifiques de niveau recherche, publiés ou non, émanant des établissements d'enseignement et de recherche français ou étrangers, des laboratoires publics ou privés. 


\title{
OPTICAL CHARACTERIZATION OF $\mathrm{Nd}^{3+}$ DOPED CaF 2 LAYERS GROWN BY MOLECULAR BEAM EPITAXY
}

\author{
L.E. BAUSA*,(1), R. LEGROS* and A. MUNOZ-YAGUE* \\ ${ }^{*}$ Laboratoire d'Automatique et d'Analyse des Systèmes du CNRS, 7 avenue du Colonel Roche, \\ F-31077 Toulouse Cedex, France
}

\begin{abstract}
Nd}^{3}+$ doped $\mathrm{CaF}_{2}$ monocrystalline films have been grown by molecular beam epitaxy using $\mathrm{CaF}_{2}$ and $\mathrm{NdF}_{3}$ evaporation on $\mathrm{CaF}_{2}$ substrates. The effect of $\mathrm{Nd}^{3+}$ concentration is studied by means of the photoluminescence signal of $\mathrm{Nd}^{3+}$ ions. The results can be compared favourably with those obtained on CaF 2 :Nd bulk crystals. For a given $\mathrm{Nd}^{3}+$ concentration a lower quantity of $\mathrm{Nd}^{3+}$ aggregate centers is observed. $\mathrm{Nd}^{3+}$ ions can therefore be efficiently incorporated as isolated $\mathrm{Nd}^{3+}-\mathrm{F}$ centers up to a concentration of 6 wt $\% \mathrm{Nd}^{3+}$ without emission quenching of their associated line at $1045.7 \mathrm{~nm}$.
\end{abstract}

1 - Introduction

$\mathrm{Nd}^{3+}$ ions are the most widely used activators in solid-state laser and stimulated emission has been observed for numerous neodynium-doped crystals, including a great number of fluoride matrices [1]. The main transition used for laser emission at room temperature takes place between ${ }^{4} \mathrm{~F}_{3 / 2}$ and ${ }^{4} /_{11 / 2}$ multiplets of $\mathrm{Nd}^{3}+$. On the other hand, some absorption lines belonging to the transition between the $4 / 9 / 2$ and $4 F_{3 / 2}$ levels overlap the emission lines of GaAs-GaAIAs semiconductor lasers. Thus, laser action from diode laser pumped $\mathrm{Nd}^{3+}$ activated crystals have been demonstrated. In this sense, association of a semiconductor diode laser with a thin film Nd-doped crystal could led to promising optoelectonic devices.

Monocrystalline thin film of $\mathrm{CaF}_{2}$ has been selected as a matrix for $\mathrm{Nd}^{3+}$ ions. Indeed laser action has been demonstrated for $\mathrm{CaF}_{2}: \mathrm{Nd}$ bulk crystals [2] and $\mathrm{CaF}_{2}$ can be epitaxially grown on semiconductor substrates [3]. In the work we present here, the epitaxial growth was carried out on $\mathrm{CaF}_{2}$ bulk crystals.

\section{2 - Experimental}

Monocrystalline thin layers of Nd-doped $\mathrm{CaF}_{2}$ were grown on (100) and (111) $\mathrm{CaF}_{2}$ substrates by molecular beam epitaxy (MBE). The substrates were mechanochemically polished, mounted on molybdenum blocks and loaded in a ultra-high vacuum chamber. The temperature of the two evaporation cells loaded with $\mathrm{CaF}_{2}$ and $\mathrm{NdF}_{3}$ was used to control the growth rate $(0.1$ to $1 \mu \mathrm{m} / \mathrm{h})$ and the impurity concentration, respectively. As demonstrated in a previous paper [4], the sticking coefficient of $\mathrm{Nd}$ is very close to unity. Here, we report on samples containing between 0.3 and $10 \mathrm{wt} \% \mathrm{Nd}^{3+}$. A good crystallinity was obtained at a substrate temperature of $500^{\circ} \mathrm{C}$, as observed by reflection high energy electron diffraction analysis during growth.

(1) On leave from Departamento de Fisica Aplicada C-IV, Universidad Autonoma de Madrid, SP-28048 Madrid Spain 
The luminescence measurements were performed at $77 \mathrm{~K}$. The luminescence was excited by the $514.5 \mathrm{~nm}$ line of an $A r^{+}$laser $(P=80 \mathrm{~mW})$ and analysed by a $1 \mathrm{~m}$ Jobin-Yvon grating spectrometer followed by a GaAs cathode photomultiplier (up to $930 \mathrm{~nm}$ ) or a cooled $\mathrm{Ge}$ photodiode for the range $1 \mu \mathrm{m}-1.1 \mu \mathrm{m}$. The presented spectra were not corrected for the response of the photodetectors.

\section{3 - Results and discussion}

Figure 1 shows a characteristic photoluminescence spectrum obtained on a sample with low doping concentration $(0.3 \mathrm{wt} \%)$ for the two spectral regions we have studied. The first one, from 850 to $930 \mathrm{~nm}$, corresponds to the $\mathrm{Nd}^{3+}$ emission lines from ${ }^{4} \mathrm{~F}_{3 / 2}->{ }^{4} / 9 / 2$ transitions of this ion ; the second, from 1040 to $1100 \mathrm{~nm}$ corresponds to the lines associated with the ${ }^{4} \mathrm{~F}_{3 / 2}$ $\left.\rightarrow 4\right|_{11 / 2}$ transition.

Before examining the features of this spectrum, we have to recall some results concerning the incorporation of $\mathrm{Nd}^{3+}$ in the $\mathrm{CaF}_{2}$ matrix.

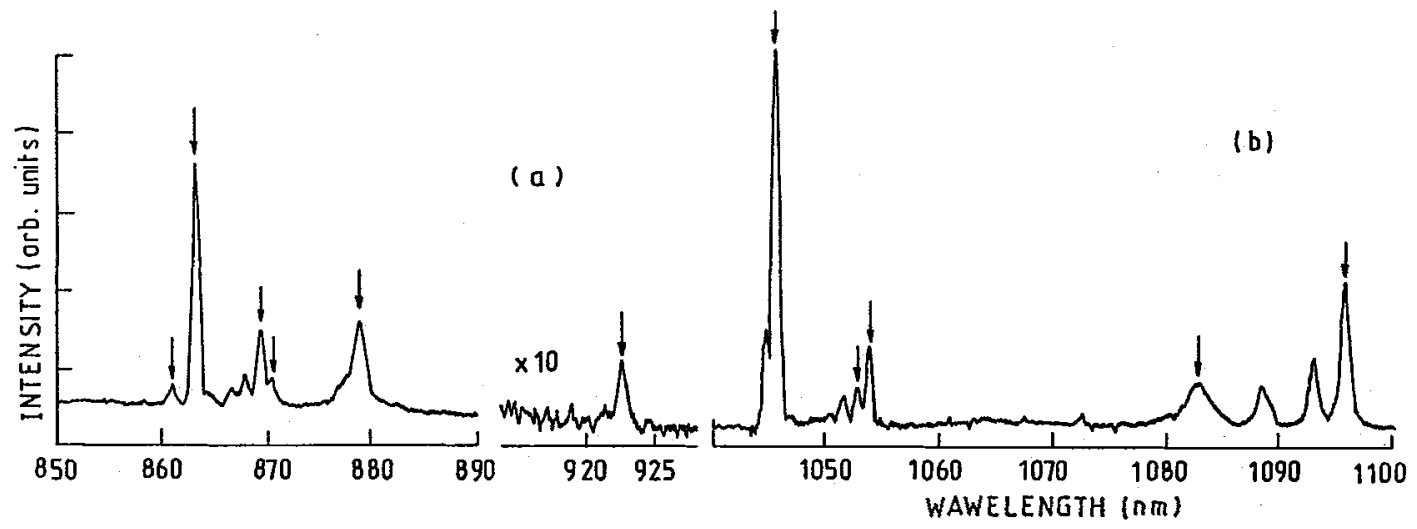

Figure 1: Luminescence spectra for a 0.3 wt $\% \mathrm{Nd}^{3}+$ doped $\mathrm{CaF}_{2}$ layer :

(a) emission lines corresponding to ${ }^{4} F_{3 / 2} \rightarrow{ }^{4} I_{9 / 2} N^{3}+$ transitions ; (b) idem for ${ }^{4} F_{3 / 2} \rightarrow{ }^{4} I_{11 / 2}$ $\mathrm{Nd}^{3}+$ transitions. Arrows show the emissions from $\mathrm{L}$ centers.

It is well known that a charge compensation mechanism is required when a rare earth trivalent ion substitutes for a divalent ion in a fluoride matrix. In our samples, the use of $\mathrm{NdF}_{3}$ as a source for $\mathrm{Nd}^{3+}$ provides the excess of $\mathrm{F}^{-}$ions in interstitial position to ensure the afore mentioned charge compensation mechanism. As in bulk crystals, this produces $\mathrm{Nd}^{3+-} \mathrm{F}^{-}$ dipoles in the $<100>$ direction, in which $\mathrm{Nd}^{3}+$ ions are in $\mathrm{C}_{4 \mathrm{~V}}$ symmetry sites [5]. Because of their large binding energy, $\mathrm{Nd}^{3}+$ and $\mathrm{F}^{-}$are associated in pairs or more complex structures [6]. Optical spectroscopy and electron paramagnetic resonance investigations have also shown that, for concentrations around $1 \mathrm{w} \% \mathrm{Nd}^{3+}$, three types of $\mathrm{Nd}$ centers exist : the $\mathrm{L}$ or tetragonal center $\left(\mathrm{Nd}^{3+-} \mathrm{F}^{-}\right)$and two orthorhombic centers, $\mathrm{M}$ and $\mathrm{N}$, which are formed by the association of two and four $L$ centers respectively [7][8].

The whole spectrum presented on figure 1 is in agreement with those already published for $\mathrm{CaF}_{2}:$ Nd bulk crystals with very diluted $\mathrm{Nd}$ concentrations [9].

The lines associated with transitions between levels of tetragonal centers are identified by an arrow. The others lines must be associated with more complex centers of orthorhombic symmetry. Due to the low concentration of $\mathrm{Nd}$, the later are weak. It must be pointed out that the spectra obtained from bulk samples with similar $\mathrm{Nd}$ concentration, show $\mathrm{M}$ and $\mathrm{N}$ emission lines much more pronounced than our epitaxial layers. 
Hereafter we will focus our attention on the line at $1045.7 \mathrm{~nm}$ ( $L$ line) because this transition is widely used when stimulated emission is investigated. The influence of Nd concentration on the relative intensity of $L$ and $N$ lines and on the absolute intensity of the emissions will be detailed.

On figure 2 three photoluminescence spectra in the $4 F_{3 / 2} \rightarrow 4 /_{11 / 2}$ emission region obtained on samples containing 0.3 to $3.7 \mathrm{wt} \%$ Nd are presented.

In this spectral region (1.04-1.06 $\mu \mathrm{m})$, the lines associated with $L, M$ and $N$ centers were previously well characterized in bulk crystals [9]. In accordance with these results, we clearly observe the lines asociated with the three types of centers (see labels in the figure). It can be noted that the relative intensity of the three emission lines changes to the benefit of the $L$ line when the $\mathrm{Nd}$ content is decreased.

When comparing our results to published data on bulk crystals $[7,9]$, it can be observed that the concentration of $L$ centers relative to aggregate centers appears to be higher in the MBE grown layers : concerning the M-type centers, the comparison is very advantageous to epitaxial layers; the ratio between $L$ centers to $M$ centers emission intensities is equal to 4 for a $1 \mathrm{wt} \% \mathrm{Nd}$ doped $\mathrm{CaF}_{2}$ crystal, whereas in our case that ratio is much higher, and this appears to be the case even for concentrations as high as 10 wt \% Nd.

According to the above considerations, the ratio between the emission intensities corresponding to $\mathrm{L}$ centers and $\mathrm{N}$ centers measures in our samples the aggregation state of the $\mathrm{Nd}^{3}+$. Figure 3 gives this ratio as a function of $\mathrm{Nd}$ content in the samples under study.

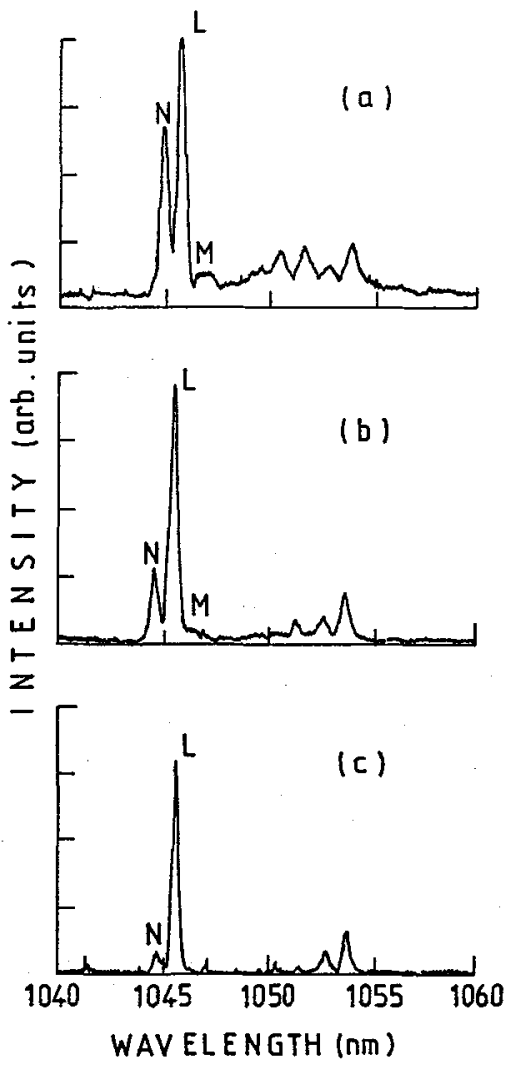

Figure 2: $\mathrm{Nd}^{3}+$ luminesence spectra in the $4 \mathrm{~F}_{3 / 2}->4 / 11 / 2$ region for layers with different $\mathrm{Nd}^{3}+$ content : (a) 3.7 wt\% ; (b) 1.1 $w t \%$ and (c) $0.3 w t \%$.

Figure 4 illustrates the influence of Nd concentration on the emission intensity of the 1045.7 $\mathrm{nm}$ peak ( $L$ line). Up to $6 \mathrm{wt} \%$, the intensity increases linearly. The results previously obtained for $\mathrm{Nd}^{3}+$ ions in $\mathrm{CaF}_{2}$ bulk crystals show that luminescence quenching is effective beyond $0.1 \mathrm{wt} \% \mathrm{Nd}^{3+}$. This final result demonstrates the superior performance of epitaxial material in comparison with bulk crystals. The low concentration of $\mathrm{M}$ and $\mathrm{N}$ aggregates allows incorporation of $\mathrm{Nd}$ at high concentration without significant quenching of the 1045.7 $\mathrm{nm}$ emission.

This tendancy of Nd ions to form mainly tetragonal centers could be explained by the growth temperature. Epitaxial growth takes place at much lower temperatures than those used for bulk crystal growth. This greatly influences the formation of aggregates wich depends on total Nd concentration and on temperature which governs solid state diffusion ; indeed, it has 
been reported that complexes $\mathrm{Nd}^{3+}-\mathrm{F}$ - become virtually immobile at temperatures less than $600^{\circ} \mathrm{C}[6]$.

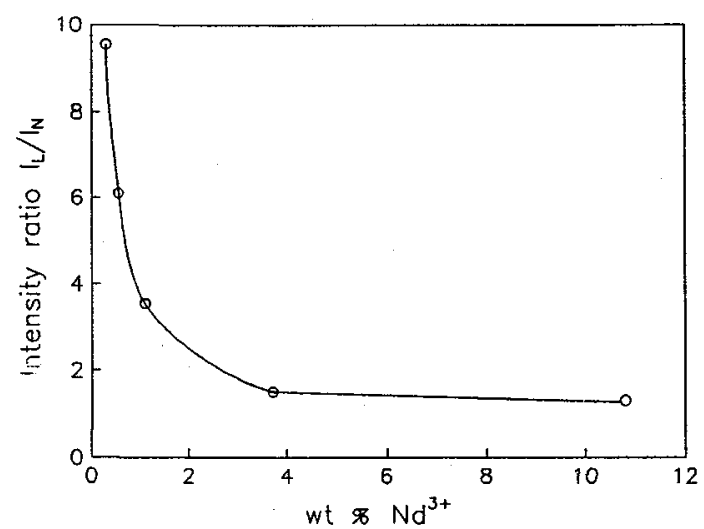

Figure 3: Intensity ratio $L_{L} / I_{N}$ calculated for the luminescence lines at 1045.7 and the $1045.7 \mathrm{~nm}$ emission line.

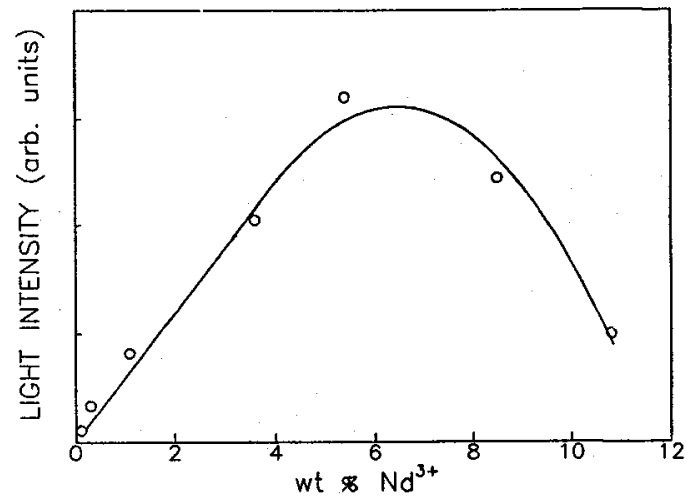

Figure 4: Emission intensity at $77 \mathrm{~K}$ as a function of $\mathrm{Nd}^{3+}$ concentration for $1044.8 \mathrm{~nm}$.

A last question is the role that crystal orientation plays in the processes of $\mathrm{NdF}_{3}$ dissociation when incorporating in the $\mathrm{CaF}_{2}$ matrix and in aggregate formation.

The $I_{L} / I_{N}$ relationship is identical for two samples grown simultaneously on (100) and (111) $\mathrm{CaF}_{2}$ oriented substrates. This can be observed from the spectra shown in figure 5(a) and 5(b) corresponding to epitaxial layers grown on $\mathrm{CaF}_{2}$ substrates with (100) and (111) orientation respectively. This result allows to deduce that $\mathrm{Nd}^{3+}$ aggregation is not dependent on the orientation of the growing surface and, hence, only bulk mechanisms related to growth temperature have an influence on the formation of $\mathrm{Nd}$ complex centers in the epitaxially grown $\mathrm{CaF}_{2}:$ Nd layers.

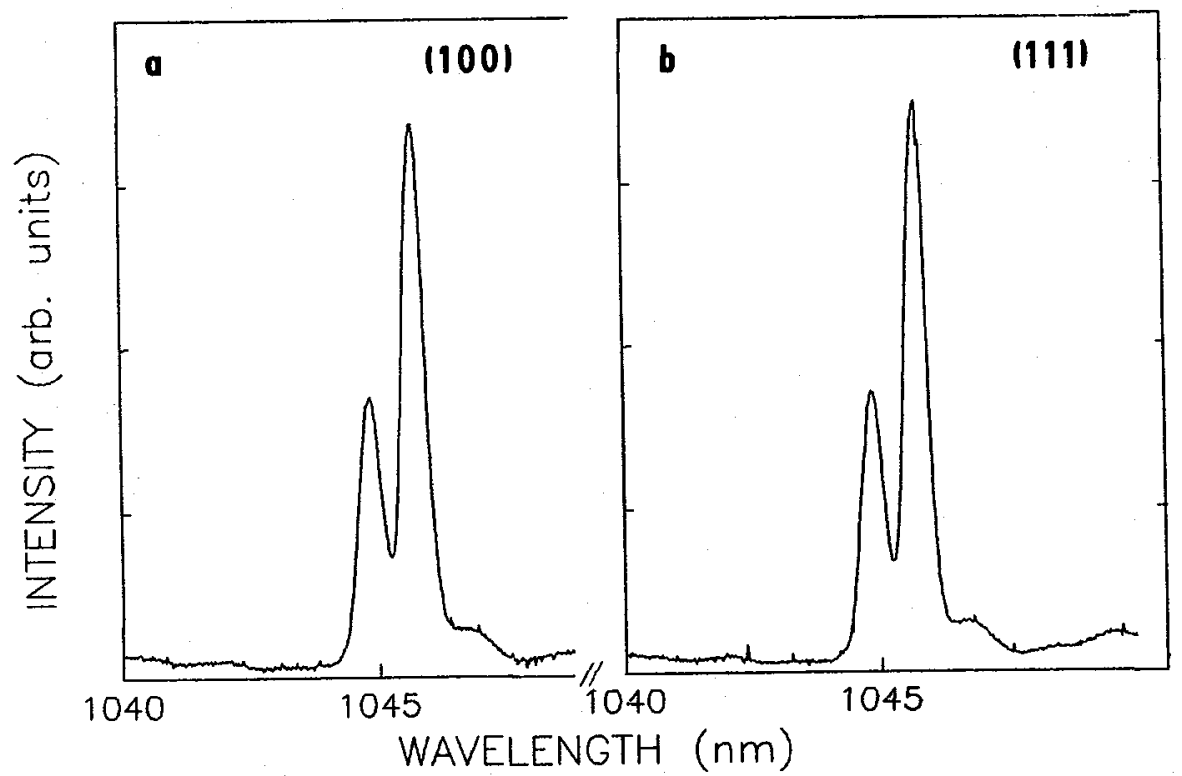

Figure 5: Photoluminescence spectra of $\mathrm{Nd}^{3}+$ in $\mathrm{CaF}_{2}$ layers grown on oriented monocrystalline substrate of $\mathrm{CaF}_{2}$. Orientation : (a) (100) and (b) (111). 


\section{4 - Conclusion}

Monocrystalline thin layers of $\mathrm{Nd}$-doped $\mathrm{CaF}_{2}$ on $(100) \mathrm{CaF}_{2}$ substrates have been epitaxially grown by MBE. Close control of the doping level was obtained by varying the flux of $\mathrm{NdF}_{3}$.

We have used photoluminescence measurements to study the incorporation of $\mathrm{Nd}$ in $\mathrm{CaF}_{2}$. Due to the charge compensation mechanism most of the $\mathrm{Nd}^{3+}$ ions forms isolated complex centers $\left(\mathrm{Nd}^{3+}+\mathrm{F}^{-}\right)$. The concentration of $\mathrm{M}$ - and $\mathrm{N}$-type aggregates is lower than that observed for moderate $\mathrm{Nd}^{3}+$ concentration (around 1 wt \%) in bulk $\mathrm{CaF}_{2}$ crystals.

The thermodynamical conditions during MBE growth (namely the low growth temperature) explain the high efficiency of $\mathrm{Nd}$ incorporation and the inability of $\mathrm{Nd}^{3}+$ to diffuse and to form more complex centers.

\section{References}

/1/ KAMINSKII, A.A, Laser Crystals, (Springer series in Optical Sciences, Springer Verlag, 1990), p.97-101.

/2/ KAMINSKII, A.A, JETP Letters, 6 (1967) 115

13/ SISKOS, S, FONTAINE, C, and MUNOZ-YAGUE, A, Appl. Phys. Lett. 44 (1984) 1146

14/ BAUSA, L.E, LEGROS, R, and MUNOZ-YAGUE, A, Appl. Phys. Lett. 59 (1991) 1

/5/ DORENBOS, P, and den HARTOG, H.W, Phys. Rev B31 (1985) 3932

/6/ OSIKO, V.V, and SHCHERBAKOV, I.A, Sov. Phys. Solid-State 14 (1971) 820

III VORONKO, Y.K, KAMINSKII, A.A, and OSIKO, V.V, Sov. Phys.-JETP 21 (1966) 295

18/ KASK, N.E, KORNIENKO, L.S, and FAKIR, M, Sov. Phys. Solid-State 6 (1964) 430

19/ FREETH, C.A, and JONES, G.D, J. Phys. C : Solid-State Physics 15 (1982) 6833 